MISES: Revista Interdisciplinar de Filosofia, Direito e Economia ISSN 2318-0811

Volume IV, Número 1 (Edição 7) Janeiro-Junho 2016: 105-119

\title{
Resposta a Barnett e Block sobre a Ética do Descasamento da Maturidade de Empréstimos
}

\author{
Laura Davidson*
}

Resumo: Davidson (2015) defende que é ético, para um banco, tomar dinheiro emprestado por um curto período de tempo e emprestar este mesmo dinheiro por um período maior. Barnett e Block (2015) discordam. Este artigo é uma resposta a Barnett e Block.

Palavras-Chave: Reservas fracionárias. Sistema bancário. Descasamento da maturidade de empréstimos.

\section{Rejoinder to Barnett and Block on the Ethics of Loan Maturity Mismatching}

\begin{abstract}
Davidson (2015) takes the position that it is ethical for a bank to borrow money for a shorter time period, and lend this same money out for a longer term. Barnett and Block (forthcoming) disagree. The present paper is a response to Barnett and Block.
\end{abstract}

Keywords: Fractional reserves. banking. loan maturity mismatching.

Classificação JEL: E42.

*Traduzido do inglês para o português por Claudio A. Téllez-Zepeda.

** Laura Davidson é mestre pela Oxford University e recebeu o Lawrence W. Fertig Prize in Austrian Economics. e-mail: davidsonlaura@hotmail.com 


\section{I - INTRODUÇÃO}

William Barnett e Walter Block ${ }^{1}$, assim como Davidson², estão completamente de acordo quanto ao sistema bancário de reservas fracionárias (FRB) ser antiético, e em que deveria ser proibido por lei em uma sociedade genuinamente livre. Se, por exemplo, A deposita dinheiro com B "à vista", isto significa que A continua a ter o direito de utilizá-lo em qualquer momento. É uma questão de lógica que A continua a ser o proprietário e o único detentor do título de propriedade a respeito do dinheiro em questão. Assim, se B empresta o dinheiro a $C$, ocorre uma violação da lei natura, independentemente da lei estatutária, ou mesmo de se $\mathrm{A}, \mathrm{B}$ e $\mathrm{C}$ concordam com este acordo. A violação ocorre porque foram criados títulos de propriedade duplicados; ou seja, tanto A quanto C controlam o mesmo dinheiro ${ }^{3}$.

No entanto, os dois conjuntos de autores diferem quanto ao caráter ético do descasamento da maturidade de empréstimos, em particular quanto à prática bancária de tomar empréstimos no curto prazo e emprestar no longo prazo (BSLL). Barnett e Block ${ }^{4}$

${ }^{1}$ BLOCK, Walter \& BARNETT II, William. Réplica a Davidson sobre a Ética do Descasamento da Maturidade de Empréstimos e o Sistema Bancário de Reservas Fracionárias. MISES: Revista Interdisciplinar de Filosofia, Direito e Economia, Vol. III, No. 2 (Jul-Dez. 2015): 411-425.

${ }^{2}$ Barnett \& Block (op. cit.) referem-se equivocadamente ao artigo de Davidson em 2014 quando se trata, de fato, do artigo de 2015. Se não há dano, não há problema.

${ }^{3}$ Ver também: HOPPE, H. H. ; HULSMANN, J. G. \& BLOCK, W. E. Against Fiduciary Media. Quarterly Journal of Austrian Economics, Vol. 1, No. 1 (1998): 19-50; BLOCK, W. E. Fractional Reserve Banking: An Interdisciplinary Perspective. In: BLOCK, Walter \& ROCKWELL, Llewellyn H. (Eds.). Man, Economy, and Liberty: Essays in Honor of Murray N. Rothbard. Auburn, AL: Ludwig von Mises Institute, 1988; e DAVIDSON, L. Fractional Reserve Banking is Indeed Fraudulent. LewRockwell.com (November 17, 2008).

4 BARNETT, W. \& BLOCK, W. E. Time deposits, dimensions and fraud. Journal of Business Ethics, Vol. argumentam que o BSLL é o caso mas geral do FRB, sendo portanto antiético. Os autores identificam um continuum entre os dois tipos de acordo contratual. Segundo esses autores, tanto no FRB quanto no BSLL, um poupador, A, deposita dinheiro com um banqueiro, B, que então o empresta a C. No caso do BSLL, A deposita fundos com B por um período especificado e B utiliza este dinheiro para emprestá-loaC porum períodode tempomaior. No FRB, a duração do empréstimo de $A$ para $B$ é zero, por ser "à vista"; isto é, A pode exigir pagamento imediato. No entanto, a estrutura dos dois tipos de contrato é essencialmente a mesma, de acordo com Barnett e Block. Assim que o empréstimo de $A$ atingir a maturidade (o que, no caso do FRB, ocorre no presente), surge um título duplicado, dado que o dinheiro que agora pertence a $C$ também é de propriedade de A.

Davidson', por outro lado, sustenta que esse continuum não existe. Em sua visão, embora o FRB seja antiético, o mesmo não vale para o BSLL. Tanto a acusação de Davidson contra o FRB quanto sua defesa do BSLL se baseiam na teoria da transferência de títulos (TTT), que Barnett e Block subscrevem 6 . Suponha que A empresta 100 dólares a B por $u m$ ano no instante $t_{0}$. Davidson pergunta o que isto significa e por que é distinto. Diferentemente do caso do FRB, A transferiu

88, No. 4 (2009): 711-716; BARNETT, W. \& BLOCK, W. E. Rejoinder to Bagus and Howden on borrowing short and lending long. Journal of Business Ethics, Vol. 100 (2011): 229-238.

5 DAVIDSON, L. Ethical Differences between Loan Maturity Mismatching and Fractional Reserve Banking: A Natural Law Approach. Journal of Business Ethics, Vol. 131 (2015): 9-18.

${ }^{6}$ Sobre a teoria da transferência de títulos, ver: EVERS, W. Toward a Reformulation of the Law of Contracts. Journal of Libertarian Studies, Vol. 1, No. 1 (1977): 3-13; ROTHBARD, M. N. The Ethics of Liberty. New York: New York University Press, 1982 (cap. 17); BARNETT, R. A Consent Theory of Contract. Cornell Law Review (1986): 1022-1033; BARNETT, R. Some Problems With Contract as Promise. Cornell Law Review (1992): 1022- 1033. 
controle total do dinheiro e, portanto, seu título para $B$, de modo que $B$ pode fazer o que desejar com esse dinheiro (assumimos, aqui, que não há restrições sobre o empréstimo). A não é mais o proprietário. Assim, de acordo com Davidson, se B empresta 100 dólares para $\mathrm{C}$ por qualquer período de tempo, digamos por dois anos, está em seu total direito de assim proceder. O que A recebe em troca? Em $\mathrm{t}_{0}$, recebe uma nota, um IOU (I Owe You - Eu Te Devo) ou uma letra de câmbio de B, que será evidência da obrigação, por parte de $B$, de retornar o montante original mais juros em $t_{1}$. No entanto, dado que nunca é possível possuir qualquer quantidade de dinheiro a ser entregue no futuro, A não recebe um título correspondente a este "dinheiro futuro". Ademais, após $t_{1}$, A não recupera a propriedade dos 100 dólares originais, tal como defendido por Barnett e Block. O que A tem é a nota, que agora apresenta a $B$ para ser reembolsado. É irrelevante de onde $\mathrm{B}$ obtém este dinheiro (dado, obviamente, que tenha sido de maneira legal). Caso fracasse em pagar, ficará inadimplente e A poderá buscar uma solução tal como faria com qualquer empréstimo em atraso. Entretanto, nunca há dois proprietários dos 100 dólares originais. Em $t_{1}$, C é o único proprietário - tal como se tornou quando B lhe transferiu o dinheiro em $\mathrm{t}_{0}$. Assim, não há nenhuma questão a respeito de títulos de propriedade duplicados ${ }^{7}$.

\footnotetext{
${ }^{7}$ Assim como Davidson, outros autores também sustentam que o BSLL é ético e que não há um continuum entre essa prática e o FRB. Esses autores utilizam um argumento de certa forma distinto, que se baseia em precedentes legais e históricos em vez da Teoria de Transferência de Títulos. Ver: BAGUS, P. \& HOWDEN, D. The legitimacy of loan maturity mismatching: A risky, but not fraudulent undertaking. Journal of Business Ethics, Vol. 90, No. 3 (2009): 399-406; BAGUS, P. \& HOWDEN, D. The Continuing Continuum problem of Deposits and Loans. Journal of Business Ethics, Vol. 106, No. 3 (2012): 295-300; BAGUS, P. \& HOWDEN, D. The economic and legal significance of "full" deposit availability. European Journal of Law and Economics, 1-12 (2012); BAGUS, P. \& HOWDEN, D. Some Ethical Dilemmas of Modern Banking. Business Ethics: A European Review, Vol. 22, No. 3 (2013): 235-245.
}

Em seu último artigo ${ }^{8}$, Barnett e Block rejeitam este argumento e continuam a defender que, em $t_{1}$, há dois proprietários para o mesmo dinheiro, a saber, A e C. Como B é o responsável por este estado de coisas, incorreria portanto em violação da lei natural e seria um "criminoso". Deu azo a dois contratos incompatíveis. Este artigo é uma resposta a essas colocações de Barnett e Block. Grande parte do argumento dos autores pressupõe que, quando Davidson utiliza certas palavras ou frases, deseja dizer uma coisa, quando na verdade quer dizer algo completamente diferente. Assim, neste artigo, começaremos com uma definição cuidadosa dos termos.

\section{II - Bens Futuros}

Primeiramente, Barnett e Block ${ }^{9}$ repreendem Davidson pela utilização do termo "bens futuros" dado que, de acordo com esses autores, tais bens não podem ter existência presente. Em qualquer momento dado, um bem futuro não pode existir. Entretanto, Davidson não discorda a este respeito. Davidson emprega a frase como mera abreviação para descrever bens que serão entregues no futuro. Reconhece por completo que não pode haver títulos para tais bens no presente. Na verdade, este é um ponto importante e central para seu argumento. No presente artigo, para evitar qualquer confusão adicional, o termo "bem (ou dinheiro) futuro" será abandonado e, em seu lugar, empregarei a frase "bem (ou dinheiro) a ser entregue no futuro", que tem precisamente o mesmo significado que Barnett e Block lhe atribuem.

\footnotetext{
${ }^{8}$ BLOCK \& BARNETT. Réplica a Davidson sobre a Ética do Descasamento da Maturidade de Empréstimos e o Sistema Bancário de Reservas Fracionárias.

${ }^{9}$ Idem. Ibidem, p. 414.
} 


$$
\text { III - RisCO }
$$

A seguir, Barnett e Block $^{10}$ acusam Davidson de concordar com o ponto de vista de que, devido ao BSLL ser arriscado, este risco exerce alguma influência sobre seu caráter ético. Embora Davidson se remeta a Bagus e Howden ${ }^{11}$ com respeito ao risco do BSLL, está claro que a autora não acredita que o risco esteja, de alguma forma, relacionado à ética do BSLL. A acusação é totalmente desprovida de mérito. Em nenhum ponto a autora sugere que o aspecto do risco do BSLL é um fato relacionado. É algo que não pode ser inferido.

\section{IV - Teoria da TransferênCIA DE TÍtulos}

Embora Barnett e Block estejam de acordo com a TTT, registram sua objeção quanto à interpretação de Davidson desta teoria, tal como proposta por Kinsella ${ }^{12}$. Sua discordância centra-se no fato de que Kinsella considera que há uma cláusula condicional implicada em todos os contratos futuros. Para voltar ao nosso exemplo anterior, suponha que A empresta dinheiro a B por um ano e que A transfere o título de seu dinheiro para $B$ em $t_{0}$. No final do ano - digamos em $t_{1}-$, a transferência dos títulos de $\mathrm{B}$ para $\mathrm{A}$ depende da condição de $B$ possuir a quantidade requerida de dinheiro para devolver. No entanto, em nenhum lugar no artigo de Davidson a autora sugere que, caso B não detenha a posse da quantidade requerida de dinheiro em $t_{1}$, isto lhe permite escapar do cumprimento de sua obrigação. Pelo contrário, em um mundo anarcocapitalista,

\footnotetext{
${ }^{10}$ Idem. Ibidem, p. 414.

${ }^{11}$ BAGUS \& HOWDEN. The legitimacy of loan maturity mismatching: A risky, but not fraudulent undertaking.

${ }^{12}$ KINSELLA, S. A Libertarian Theory of Contract: Title Transfer, Binding Promises, and Inalienability. Journal of Libertarian Studies, Vol. 17, No. 2 (2003): 11-37.
}

provavelmente B enfrentaria a prisão civil. Na verdade, a autora apenas afirma um fato óbvio: Se B não possuir o dinheiro ou outros ativos em $t_{1}$, será logicamente impossível que reembolse A nesse momento do tempo.

Entretanto, Barnett e Block criticam Davidson a este respeito, dado que Kinsella adere ao princípio de que contratos de desempenho específicos são inaplicáveis devido à inalienabilidade da vontade, uma posição também adotada por Murray Rothbard (1926-1995) ${ }^{13}$. Em contraste, o professor Block adota a posição de que contratos de desempenho podem ser executados independentemente da alienabilidade da vontade, ou de sua falta, sendo o exemplo mais extremo aquele do contrato de escravidão voluntário ${ }^{14}$. Barnett

${ }^{13}$ ROTHBARD. The Ethics of Liberty, cap. 17.

14 De acordo com Block, "Ademais, o contrato de escravidão voluntária não é uma 'mera' promessa. Mais propriamente, é um contrato bona fide no qual a consideração fica de mãos cruzadas; quando é revogado, ocorre roubo. Se você paga 1 milhão de dólares pelo direito de me escravizar e eu gasto esse dinheiro, trabalho durante uma semana em sua plantação, mudo de ideia, escapo e as forças da lei e da ordem se recusam a me entregar de volta a você, então terei, desta forma, roubado essa quantia de dinheiro tal como se tivesse arrombado seu cofre e fugido. É difícil ver por que este acordo comercial não cumpre com as especificações da teoria de "transferência de títulos" para os contratos do próprio Rothbard" (BLOCK, W. E. Toward a Libertarian Theory of Inalienability: A Critique of Rothbard, Barnett, Gordon, Smith, Kinsella and Epstein. Journal of Libertarian Studies, Vol. 17, No. 2 (Spring 2003): pp. 39-85. Disponível em: <http://www.mises.org/journals/jls/17_2/17_2_3.pdf >). Ver também: BLOCK, W. E. Market Inalienability Once Again: Reply to Radin. Thomas Jefferson Law Journal, Vol. 22, No. 1 (Fall 1999): 37-88. Disponível em: <http://www.walterblock.com/publications/ market_inalienability.pdf>; BLOCK, W. E. Alienability, Inalienability, Paternalism and the Law: Reply to Kronman. American Journal of Criminal Law, Vol. 28, No. 3 (Summer 2001): 351-371. Disponível em: $<$ http://www.walterblock.com/publications/reply_to_ kronman.pdf $>$; BLOCK, W. E. A Libertarian Theory of Secession and Slavery. (Jun 10, 2002). Disponível em: $<$ http://libertariantruth.wordpress.com/2006/12/08/alibertarian-theory-of-secession-and-slavery/>; BLOCK, W. E. Are Alienability and the Apriori of Argument 
e Block sugerem que, como Davidson elogia Kinsella por seu trabalho, a autora também endossa o mesmo princípio. Assim, conforme argumentam, caso ocorra o caso de que contratos de desempenho não possam ser executados, isso invalida toda a sua posição.

No entanto, o argumento de Barnett e Block dirige-se contra um espantalho. Primeiramente, o mero fato de Davidson elogiar Kinsella não indica que concorda com tal autor em todos os aspectos. Em nenhuma parte de seu artigo a autora sugere acreditar que os contratos de desempenho não podem ser executados.

Em segundo lugar, embora Rothbard ${ }^{15}$ e Kinsella ${ }^{16}$ não acreditem que um ator possa ser obrigado a agir contra sua vontade, esses autores não argumentam que o devedor pode sair impune caso o dinheiro já tenha sido recebido. Pelo contrário, deverá devolver os montantes em questão, mais quaisquer juros e multas previamente acordados e, caso não seja capaz de fazê-lo, então será um ladrão.

Assim, em terceiro lugar, o que é mais importante, é irrelevante mesmo se alguém aceita a posição de Rothbard. Afinal de contas, no caso do contrato de empréstimo, o desempenho exigido do recebedor quando o empréstimo vence - a saber, retornar uma quantidade equivalente ao empréstimo inicial mais os juros - é precisamente o mesmo que se exigia caso falhasse no cumprimento em primeiro lugar. $O$ argumento de Barnett e Block é discutível.

Para fins argumentativos, suponha que se endosse o princípio de que o tomador do empréstimo não pode ser obrigado a cumprir contra sua vontade. Qual seria o efeito disto? Absolutamente nenhum. Todos os tomadores de empréstimo recebem pagamento na forma do empréstimo. Assim, se um recebedor

Logically Incompatible? Dialogue, Vol. 1, No. 1. (2004). Disponível em: <http://www.uni-svishtov.bg/ dialog/2004/256gord6.pdf $>$.

${ }^{15}$ ROTHBARD. The Ethics of Liberty.

${ }^{16}$ KINSELLA. A Libertarian Theory of Contract: Title Transfer, Binding Promises, and Inalienability. decide não cumprir, precisará devolver ao credor o montante original mais os juros acordados no contrato, caso contrário será um ladrão. Entretanto, isto significa que deverá fazer exatamente o que se esperava que cumprisse em primeiro lugar. Assim, no caso do contrato de empréstimo, é irrelevante qual posição se adote; isto é, ao lado da perspectiva de Kinsella e Rothbard, ou então do ponto de vista do professor Block. A inalienabilidade da vontade não tem qualquer influência sobre o assunto.

Qualquer tomador de empréstimo que deixe de pagar será um criminoso e isto será verdade independente de se a falha se deve a um ato premeditado e deliberado, ou de se há circunstâncias que o devedor considera que estão além de seu controle. Em uma economia genuinamente livre, contratos de empréstimo são completamente executáveis e devedores caloteiros são passíveis de responsabilização. Em $t_{1}$, no exemplo acima, B é obrigado a transferir o título de 100 dólares mais juros para A e, caso não o faça, será um criminoso - independente da razão. Entretanto, o que Davidson sempre sustentou é que o título a este dinheiro em particular não é o mesmo, nunca foi o mesmo e nunca será o mesmo título correspondente aos 100 dólares originais que A emprestou a $B$ em $t_{0}$. Isto é discutido com mais detalhes no que segue.

A seguir, Barnett e Block ${ }^{17}$ levantam a questão da maneira como Davidson emprega o termo "promessa". Para Barnett e Block, uma promessa difere de uma obrigação contratual. Ilustram esta diferença com o seguinte exemplo: um homem promete a sua esposa um carro como presente de Natal, mas então decide não lhe dar o veículo. Por outro lado, um homem paga 10.000,00 dólares a um vendedor de carros, que não entrega o veículo. O primeiro caso, dizem Barnett e Block, sendo apenas uma promessa, não é executável dado que, definitivamente, não é

17 BLOCK \& BARNETT. Réplica a Davidson sobre a Ética do Descasamento da Maturidade de Empréstimos e o Sistema Bancário de Reservas Fracionárias, p. 417. 
ilegal, porém o segundo caso conforma uma obrigação contratual e o vendedor de carros é, dessa maneira, um criminoso. Devemos observar que Davidson concorda totalmente com as conclusões inferidas. O que temos aqui é simplesmente a situação que esses autores definem o termo "promessa" de modo diferente. No artigo de Davidson, a palavra "promessa" significa precisamente a mesma coisa que uma obrigação contratual. Sem embargo, a autora está perfeitamente de acordo em aceitar a definição de Barnett e Block - portanto abandona o uso dessa palavra de agora em diante e coloca, em seu lugar, a expressão "obrigação contratual". Assim, em $t_{1}$, B se encontra contratualmente obrigado a devolver 100 dólares mais juros para A. Nada disto, contudo, modifica sua análise, conforme será demonstrado abaixo.

Finalmente, é necessário discutir o emprego da palavra "reivindicação". Tal como Rothbard observa ${ }^{18}$, este termo apresenta dois significados distintos. Por um lado, pode significar um direito, um IOU, uma letra de câmbio, um título, um certificado de depósito, etc. Todos esses termos significam essencialmente a mesma coisa; a saber, evidência de uma transação de crédito que confere uma obrigação ao emissor, que deverá pagar uma determinada quantia em uma data futura. Por outro lado, o termo "reivindicação" pode se referir a uma participação de propriedade, como quando um minerador afirma ter pretensão sobre uma terra para garimpo, ou um colono reivindica terras não possuídas anteriormente por outro indivíduo.

No primeiro caso, um direito - uma nota - coloca uma obrigação sobre o devedor, porém isso não é evidência de propriedade de coisa alguma, ao menos não até o vencimento. Por que? Porque o dinheiro a ser transferido corresponde a dinheiro que será entregue no futuro. Assim, um tal direito não é um título.

${ }^{18}$ ROTHBARD, M. N. Man, Economy and State with Power and Market. Auburn, AL: Ludwig von Mises Institute, 2004 [1962], p. 800.
Portanto, quanto A recebe um direito - uma nota - em $\mathrm{t}_{0^{\prime}}$ isto não é uma reivindicação de propriedade.

No segundo caso, uma participação de propriedade é um título. Representa a reivindicação do proprietário a respeito da propriedade em questão. Assim, em $t_{1^{\prime}}$ quando A reivindica os 100 dólares mais juros, afirma que agora possui dinheiro nessa quantia, ou, colocando de outra forma, possui um título com respeito àquele montante que, atualmente, encontra-se sob posse de $B$, e que $B$ está legalmente obrigado a entregar ${ }^{19}$.

O problema surge quando dois significados diferentes para um termo se confundem, porque então é possível imaginar que a reivindicação de $\mathrm{A}$ em $\mathrm{t}_{0}$ é a mesma que em $t_{1}$. Não é. Para evitar mais confusões, doravante evitarei o emprego deste termo e referir-me-ei a uma reivindicação, no primeiro sentido, como uma nota, e uma reivindicação, no segundo sentido, como um título ou participação de propriedade.

Resumindo:

1. Estritamente, não existem bens futuros; o que há são somente bens que serão entregues no futuro.

2. Risco, ou sua ausência, não é um fator material na decisão a respeito do caráter ético de um empréstimo.

3. A questão de se se aceita ou não a perspectiva de Rothbard acerca de contratos de desempenho é irrelevante no contrato de empréstimo. Todos os contratos de empréstimo são executáveis, inde-

${ }^{19}$ Rothbard (op. cit.) afirma: “Um título com respeito a um dinheiro futuro é uma letra de câmbio - uma evidência de uma transação de crédito. $O$ detentor da letra - o credor - a resgata na data estipulada em troca de dinheiro pago pelo devedor. Um título com respeito a dinheiro presente, entretanto, é um bem completamente diferente. Não é evidência de uma transação incompleta, uma troca de um bem presente por um bem futuro, tal como a letra; é uma evidência simples da propriedade de um bem presente. Não é algo incompleto, ou uma troca no tempo do mercado. Assim, apresentar esta evidência para resgate não é a concretização de uma transação, ou o equivalente a um credor cobrando seu empréstimo; é uma simples restauração de posse do próprio bem de um homem". 
pendentemente da posição que se adota a respeito de contratos de desempenho em geral.

4. No caso do BSLL, o tomador do empréstimo se encontra obrigado por contrato a pagar ao credor original no vencimento da dívida e, caso não o faça, será um criminoso.

5. O termo "reivindicação" apresenta dois significados distintos. Por um lado, pode ser definido como uma nota, ou obrigação, etc. Por outro lado, pode indicar reivindicação de propriedade. Uma nota não é uma participação de propriedade.

Voltando ao exemplo acima, vamos assumir, primeiramente, que não há estipulações sobre o empréstimo. Neste caso, quanto A empresta 100 dólares a $\mathrm{B}$ em $\mathrm{t}_{0^{\prime}}$ o título sobre esse dinheiro é inteiramente transferido para $B$, dado que não se impõem restrições sobre essa propriedade. Como B agora possui o dinheiro em definitivo, sem restrições, está claro que pode fazer com ele o que desejar, inclusive queimá-lo ou destruí-lo. Entretanto, se esta é uma ação legítima por parte de $\mathrm{B}$, então também lhe deve ser lícito emprestar o mesmo dinheiro a $C$ em um novo contrato de empréstimo com qualquer termo que lhe for conveniente ${ }^{20}$. Antes de emprestá-lo a C, é seu dinheiro, e de ninguém mais (inclusive $\mathrm{A}$ ). Ademais, assim que o empresta a $C$, o título se transfere novamente, desta vez para C. Em nenhum ponto deste processo A mantém qualquer interesse a respeito desses 100 dólares em particular.

O que A recebe em troca por ter emprestado os 100 dólares a B? Recebe uma nota de $B$, que por contrato obriga $B$ a reembolsá-lo em $t_{1}$. Isto significa que, em $t_{1}, B$ precisa possuir 100 dólares mais os juros e transferir seu título para A. Entretanto, este não é nem nunca pretendeu ser o título correspondente aos 100 dólares originais que $A$ emprestou a $B$ o que foram emprestados a C. Se B falha em cumprir

\footnotetext{
${ }^{20}$ Barnett e Block respondem que não há problema em queimá-lo porque não é um ato criminoso, porém emprestá-lo a prazo é fraude. Mais adiante neste artigo, mostrar-se-á que se trata de uma posição insustentável.
}

esta obrigação contratual, encontra-se inadimplente e é um criminoso. Neste caso, quaisquer outros ativos que possua podem ser apreendidos por A e, caso não tenha ativos, então será conduzido à prisão civil.

Assim, em $t_{0^{\prime}}$ A recebe uma nota. Em $t_{1^{\prime}}$ a nota vence e agora se torna outra coisa, a saber, um título correspondente a 100 dólares mais juros que lhe são devidos. Entretanto, a nota nunca é um título relativo aos 100 dólares originais. Ademais, antes de $t_{1}$, não são uma reivindicação no sentido de propriedade. Mais propriamente, essa nota é evidência de uma obrigação contratual que deve ser cumprida por B. Por que Barnett e Block acreditam que A poderia possuir - ter o título a - estes 100 dólares quando o contrato é assinado em $\mathrm{t}_{0} \mathrm{e}$ os 100 dólares somente são passíveis de entrega no futuro, em $\mathrm{t}_{1}$ ? Nenhum credor detém a propriedade do dinheiro que empresta. É isso que torna o empréstimo diferente de um depósito à vista, no qual o depositante nunca abre mão da propriedade. Com um empréstimo, contudo, o emprestador abre mão da propriedade em troca de uma nota, que é uma obrigação contratual correspondente a dinheiro a ser entregue no futuro.

Barnett e Block ${ }^{21}$ sugerem que B realizou dois contratos incompatíveis e respondem com o seguinte cenário:

$\mathrm{Y}$ concorda em encontrar-se com $\mathrm{X}$ no momento $t_{1}$ e na cidade $x$. Ao mesmo tempo, concordou em cantar no casamento de $Z$ em outra cidade distante, $\mathrm{Z}^{22}$. É óbvio que $\mathrm{Y}$ não pode cumprir ambos os contratos ${ }^{23}$.

Aqui, Barnett e Block estão completamente certos. Estou totalmente de acordo em que esses dois contratos são incompatíveis e

${ }^{21}$ BLOCK \& BARNETT. Réplica a Davidson sobre a Ética do Descasamento da Maturidade de Empréstimos e o Sistema Bancário de Reservas Fracionárias, p. 416418.

${ }^{22}$ Com base nesta abreviação, $t_{0}$ seria o presente, $t_{1}$ seria daqui a um ano, $\mathrm{t}_{10}$ daqui a dez anos e assim por diante.

${ }^{23}$ BLOCK \& BARNETT. Réplica a Davidson sobre a Ética do Descasamento da Maturidade de Empréstimos e o Sistema Bancário de Reservas Fracionárias, p. 418. 
em que Y é um criminoso. Não tenho o que discutir. Entretanto, o que torna este exemplo específico diferente é que para Y é logicamente impossível estar em dois lugares ao mesmo tempo. No caso do BSLL, entretanto, não é logicamente impossível que o intermediário, $\mathrm{B}$ no nosso caso, possa encontrar os 100 dólares para pagar a A. Em uma economia de mercado, pode recorrer a D, ou E, ou F. Ademais, supondo que seja um bom empreendedor, terá antecipado corretamente com respeito à preferência temporal social e encontrará um novo empréstimo. Dessa forma, não ficará inadimplente e, portanto, não será um criminoso. Caso falhe, por ter errado em sua previsão e se, ademais, não possuir outros ativos, então irá para a prisão. Como isto difere do caso em que um empreendedor que toma um empréstimo investe em um projeto de algum tipo e falha em ter os fundos necessários à sua disposição no vencimento do empréstimo? Também ficaria inadimplente e na mesma situação. Barnett e Block poderiam responder que isso não seria ilícito se a duração antecipada para o projeto do empreendedor corresponder ao prazo do empréstimo. É, contudo, ilícito, diriam esses autores, se o período de produção for maior que o prazo do empréstimo. Não tenho dúvidas de que esses autores argumentariam que isto é semelhante às ações daqueles que se engajam em BSLL. Por que? A menos que o empréstimo proíba especificamente que o empreendedor invista em um projeto que sabe que será mais longo, por que isto seria ilícito? Se o credor não lhe impõe restrições, por acaso não é dinheiro seu, para fazer o que bem entender?

É verdade que, às vezes, o tomador de empréstimo pode se encontrar proibido por contrato de utilizar o dinheiro para determinados propósitos. Certamente, no caso do empreendedor, caso concorde de antemão que o projeto e o empréstimo devem corresponder temporalmente, então deverá seguir esses termos. Caso ignore esta estipulação, de fato irá se engajar em um ato ilícito. De modo semelhante, se o acordo entre A e B estipula claramente que B não pode se engajar em BSLL, então emprestar esse dinheiro a $C$ por uma duração maior seria proibido. No entanto, empréstimos ordinários não têm essa condição. Normalmente, não há acordo implícito ou explícito para esse efeito.

A seguir, Barnett e Block afirmam ${ }^{24}$ :

Em contraste, suponha que B simplesmente torra o dinheiro confiado a ele por $\mathrm{A}^{25}$. Será que agora $\mathrm{B}$ aumentou o risco de não ser capaz de reembolsar A daqui a um ano? Sim, obviamente. Ele poderia devolver o dinheiro a $\mathrm{A}$ mais facilmente caso o tivesse enfiado debaixo do colchão, ou emprestado a $C$ por um ano, ou mesmo por dez anos ${ }^{26}$. No entanto, B cometeu uma fraude ao destruir o dinheiro que A confiou a ele durante um ano? Não. A despeito de parecer um pouco estranho, neste caso B não terá cometido fraude. Não se envolveu em dois contratos incompatíveis, um dos quais precisa necessariamente quebrar para satisfazer o outro.

Devo dizer que estou perplexa com esta declaração. Decerto é estranho que Barnett e Block acreditem que é permissível para B torrar o dinheiro - ou queimá-lo, destruí-lo mas não lhe seria permitido emprestá-lo a $C$ com base em constituir fraude. Certamente, se o primeiro caso é permissível, então a fortiori a segunda situação também deveria ser. Entretanto, em cada caso, por que deveria "necessariamente não ser capaz de cumprir" com qualquer coisa. Se B queimar o dinheiro, ou se o emprestar a $C$, é verdade que pode não saber, de antemão, como exatamente irá reembolsar A em um ano. Entretanto, em uma economia de mercado, claramente não é

${ }^{24}$ BLOCK \& BARNETT. Réplica a Davidson sobre a Ética do Descasamento da Maturidade de Empréstimos e o Sistema Bancário de Reservas Fracionárias, p. 418419.

${ }^{25}$ Assumimos que esta ação não era proibida pelo contrato entre A e B.

${ }^{26}$ Neste caso, B pode ao menos com o valor presente descontado do dinheiro a ser recebido daqui a uma década, para servir como garantia para outro empréstimo de um A2. Isto é melhor do que papelmoeda queimado. 
verdade afirmar que necessariamente fracassará em cumprir com isto ${ }^{27}$.

Mais ainda, considere o seguinte cenário: suponha que B tenha obtido 100 dólares, que coloca sob o colchão, e que ademais obtém 100 dólares de um empréstimo de um ano que contrai com A. Digamos que receba os 100 dólares de $\mathrm{A}$ e os colocque em uma gaveta. Agora, B possui um total de 200 dólares à sua disposição: 100 dólares sob o colchão e 100 dólares na gaveta. Se B toma emprestados os 100 dólares de A, agora na gaveta, e os queima, isto é lícito de acordo com Barnett e Block. Ademais, se toma os 100 dólares sob seu colchão e os empresta a C por dois anos,

\footnotetext{
${ }^{27}$ Há uma situação específica na qual necessariamente fracassará; isto é, quando não há uma economia de mercado. Por exemplo, suponha que A, B e C são os únicos atores que vivem em uma ilha deserta. Como não há $\mathrm{D}^{\prime}$ s, $\mathrm{E}^{\prime} \mathrm{s}$ ou $\mathrm{F}^{\prime} \mathrm{s}$, necessariamente $\mathrm{B}$ fracassará em assegurar outro empréstimo para $t 1$ a menos que $C$ concordeem devolverseuempréstimo antecipadamente nesse momento. De maneira interessante, esta é a situação na qual Davidson sustenta que a descoordenação do BSLL surge. Deve ser observado que tanto Block quanto Davidson concordam com a noção de que se atos antiéticos são legalizados, então isto leva à descoordenação econômica e ao fracasso do mercado. Da mesma maneira, em um mercado livre, no qual nenhuma ação antiética é legalizada, não pode haver fracasso do mercado (ver: BLOCK, W. E. \& DAVIDSON, L. 2011. The Case Against Fiduciary Media: Ethics is the Key. Journal of Business Ethics. Vol. 98. No.3 (2011): 505-511). Por esta razão, Barnett e Block (BARNETT, W. \& BLOCK, W. E. Crash and Carry: Financial Intermediaries, the IntertemporalCarry Trade, and Austrian Business Cycles. Etica y Politica / Ethics and Politics, Vol. 11, No. 1 (2009): 455-469) afirmam que o BSLL leva a ciclos de negócios, enquanto Davidson afirma que isto não ocorre. As duas posições parecem ser consistentes com os pontos de vista desses autores acerca da ética do BSLL. Entretanto, Davidson critica o argumento econômico de Barnett e Block de que o BSLL provoca ciclos de negócios por ser baseado em um exemplo no qual os atores não operam no mercado, mas sim isoladamente, tal como na situação específica mencionada acima (DAVIDSON, L. Economic Consequences of Loan Maturity Mismatching in the Unhampered Economy. Quarterly Journal of Austrian Economics, Vol. 17, No. 1 (2014): 67-91). Davidson argumenta que, no isolamento, de fato a descoordenação emerge, porém somente neste caso especial.
}

isto novamente está perfeitamente correto, de acordo com Barnett e Block. Afinal de contas, não era o dinheiro de A que estava sob o colchão. Obviamente, ao fazer isto, fica com zero dólares à disposição com os quais reembolsar A, masnãoimporta; está tudo sobre a mesa. Suponha, agora, que B faz exatamente a mesma coisa, com exceção de um detalhe: antes de queimar e emprestar o dinheiro, troca os 100 dólares que estavam na gaveta com os 100 dólares que estavam debaixo do colchão. O resultado líquido é precisamente o mesmo: queima 100 dólares, empresta 100 dólares, fica com zero dólares. Aparentemente, agora cometeu um ato criminoso. O problema não reside, obviamente, em ter queimado os 100 dólares que tinha originalmente. Entretanto, recebeu 100 dólares de A e os emprestou a C por dois anos, o que corresponde a uma fraude, de acordo com Barnett e Block. As mesmas ações, o mesmo resultado - com notas de 100 dólares diferentes -, mas um cenário é considerado um ato criminoso e o outro não é.

Por que deveria fazer diferença quais 100 dólares utiliza para cada propósito? Obviamente, não faz diferença.

\section{V - TTT Aplicada a EMpréstimos a Prazo}

Barnett e Block têm objeções com respeito à seguinte passagem de Davidson ${ }^{28}$ :

Suponha que A empresta a B 100 dólares durante um ano, tal como antes, e que B empresta imediatamente este dinheiro para $C$ por um período de 2 anos. Há uma duplicação de títulos de propriedade, conforme argumentam Barnett eBlock? Não, não há. $\mathrm{A}$, que inicialmente possui os 100 dólares, transfere sua titularidade para B, em troca da qual A recebe o título a um direito - uma letra de câmbio ou nota promissória - que estabelece que B promete reembolsar

${ }^{28}$ BLOCK \& BARNETT. Réplica a Davidson sobre a Ética do Descasamento da Maturidade de Empréstimos e o Sistema Bancário de Reservas Fracionárias, p. 421 
A dentro de um ano. $B$ transfere o dinheiro e seu título para $C$ e, em troca, $B$ recebe o título para uma reivindicação diferente, a qual estipula que $C$ promete devolver o dinheiro em dois anos. Em conjunto, há três títulos para três bens distintos, nenhum dos quais é uma duplicata. Dois destes bens são reivindicações e o outro corresponde aos 100 dólares. A possui uma reivindicação contra B; B possui uma reivindicação diferente contra C; e C possui os 100 dólares.

Barnett e Block não gostam do emprego da palavra "promessa". Entretanto, conforme explicado anteriormente, Davidson emprega a palavra para significar "obrigação contratual". Assim, podemos tranquilamente substituir por esta frase e, contrariamente às colocações de Barnett e Block, isso não altera em nada o significado da passagem acima, ao menos não da maneira como Davidson originalmente pretendia. De fato, a autora agradece a Barnett e Block por sugerirem um termo que é menos ambíguo.

Outra área de ambiguidade é o significado de "reivindicação". A definição de Barnett e Block significa um título ou reivindicação de propriedade, que confundem com a palavra "reivindicação" na passagem acima, onde significa uma nota. Davidson emprega o termo para denotar a evidência da obrigação a ser realizada por B para e em nome de A. No caso do BSLL, A tem uma reivindicação contra $B$, pois $B$ está obrigado a pagar 100 dólares mais juros para A em $t_{1}$. Ademais, da mesma forma, B tem uma reivindicação contra $C$ para receber em $t_{2}$. No entanto, nenhuma dessas obrigações são títulos ou denotam interesses de propriedade. Mais propriamente, são notas.

A passagem acima pode, portanto, ser reescrita colocando "obrigação contratual" no lugar de "promessa" e "nota" no lugar de "reivindicação". Evitaremos a utilização da palavra "reivindicação" empregando "título" para denotar uma reivindicação de propriedade. Devemos notar que uma nota é, em si mesma, um bem. Assim, embora não seja um título com respeito a alguma coisa, sem embargo tem um título; isto é, a nota é possuída por alguém. A passagem agora fica: Suponha que A empresta a B 100 dólares durante um ano, tal como antes, e que B empresta imediatamente este dinheiro para $\mathrm{C}$ por um período de 2 anos. Há uma duplicação de títulos de propriedade, conforme argumentam Barnett e Block? Não, não há. $\mathrm{A}$, que inicialmente possui os 100 dólares, transfere sua titularidade para $\mathrm{B}$, em troca da qual A recebe o título a uma nota que estabelece que B está contratualmente obrigado a reembolsar $\mathrm{A}$ dentro de um ano. B transfere o dinheiro e seu título para $\mathrm{C}$ e, em troca, $\mathrm{B}$ recebe o título para uma nota diferente, a qual estipula que C está contratualmente obrigado a devolver o dinheiro em dois anos. Em conjunto, há três títulos para três bens distintos, nenhum dos quais é uma duplicata. Dois destes bens são notas e o outro corresponde aos 100 dólares. A possui uma nota contra B; B possui uma nota diferente contra C; e C possui os 100 dólares.

Vamos assumir que o empréstimo não envolve nenhuma estipulação. No exemplo acima, A abre mão para sempre da propriedade dos 100 dólares que empresta a B. Por que? Porque, caso não fosse assim, então não será dinheiro de B. Caso não seja, então B não poderia trocá-lo ou, para colocar de outra maneira, utilizá-lo como dinheiro. Tudo o que poderia fazer seria, talvez, pendurar a nota de 100 dólares em uma parede ou mostrála a seus amigos. Entretanto, para utilizá-la como dinheiro, precisa ser capaz de trocá-la livremente, o que é precisamente o que faz quando a troca com $C$. O que $A$ recebe em troca? Recebe uma nota de $B$, que obriga $B$ a lhe pagar 100 dólares mais juros em $t_{1}$. No entanto, enquanto esta nota é, em si mesma, um bem, que é possuído, e isto significa que sob certas circunstâncias a nota pode ser comercializada em um segundo mercado, a nota não é um título correspondente aos 100 dólares dados originalmente a $\mathrm{B}$, como dizem Barnett e Block. A propriedade com respeito a esses 100 dólares foi transferida em $\mathrm{t}_{0}$ e A não retém nenhum interesse sobre ela. De 
maneira semelhante, quando B troca os 100 dólares por uma nota de $C$, que vence em $t_{2^{\prime}}$ novamente isto não é um título. Ambas essas notas têm títulos - isto é, são possuídas -, mas não são títulos com respeito aos 100 dólares originais. Não há duplicação de propriedade. Isto pode ser ilustrado no diagrama abaixo:

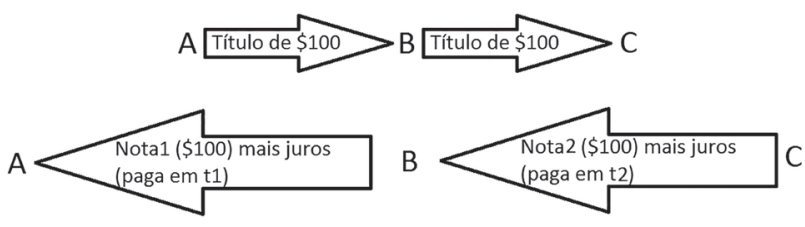

O que acontece se há estipulações no empréstimo tais que A e B concordam que $B$ não pode emprestar dinheiro a $C$ por mais do que um ano; em outras palavras, concordam contratualmente que B não pode cometer BSLL. É claro que muitos dos empréstimos não são estruturados desta maneira. Entretanto, este seria um contrato perfeitamente legítimo e, com uma tal estipulação, o BSLL seria proibido. Entretanto, isto não ocorre por causa de um problema de duplicação de títulos. Neste caso, A retém um interesse de propriedade sobre os 100 dólares originais, juntamente com B, até o ponto no qual os 100 dólares são trocados com $\mathrm{C}^{29}$. Entretanto, tal como no exemplo acima, a nota de $A$, que recebe em $t_{0^{\prime}}$ não é um título. É, simplesmente, evidência de uma obrigação contratual que deve ser cumprida em $t_{1}$. Quando os 100 dólares são transferidos para C (por um ano somente, não por dois, dado que o descasamento da maturidade de

\footnotetext{
${ }^{29}$ Conforme Rothbard afirma (ROTHBARD. The Ethics of Liberty, p. 146): “Um outro ponto importante: em nosso modelo de transferência de títulos, uma pessoa deveria ser capaz de vender não somente a totalidade do título a respeito dessa propriedade, mas também parte dessa propriedade, retendo o restante para si mesma ou outros a quem garante ou vende essa parte do título". Neste caso, A permanece como proprietário de uma parte dos 100 dólares, com B como proprietário principal. Em efeito, A possui uma cláusula restritiva sobre o dinheiro que transfere para $\mathrm{B}$, com respeito a qualquer acordo com $\mathrm{C}$. Assim que o título tiver sido transferido para C, tanto A quanto B perderão todos os interesses de propriedade sobre esse dinheiro.
}

empréstimos não se permite neste caso), tanto A quanto B abrem mão de seus interesses de propriedade e o título é transferido por completo para C. Finalmente, B recebe uma nota de $C$ que vence em $t_{2}$. Voltando ao empréstimo monetário, Barnett e Block argumentam o seguinte ${ }^{30}$ :

Reconsidere o ponto de Davidson de que "A possui um direito de reivindicação [nota] contra B; B possui um direito de reivindicação [nota] diferente contra C; e C possui os 100 dólares". Isto é de fato verdadeiro. Entretanto, somente no momento temporal inicial $t_{0}$ e não depois que se passou o período de um ano. Assim, um ano depois, em $t_{1}$, em nítido contraste, A possui agora um título de propriedade legítimo com respeito àquela quantidade de dinheiro. Mas C também possui. Se isso não for uma duplicação, então não existe nada mais que possa ser. Ou seja, a propriedade que $\mathrm{A}$ possui na forma de uma reivindicação [nota] contra B transforma-se, ao término do ano, em propriedade sobre os 100 dólares, enquanto a propriedade, na forma de uma reivindicação, expirou.

Este é o ponto problemático com o argumento de Barnett e Block. O problema com esta linha de pensamento, entretanto, é que a nota que $\mathrm{A}$ recebeu de $\mathrm{B}$ em $\mathrm{t}_{0^{\prime}}$ quando entregou o dinheiro, não se refere, em $t_{1}$, ao mesmo interesse de propriedade do qual A abriu mão em $t_{0}$. A abriu mão por completo dessa reivindicação de propriedade quando a transferiu para B. Caso não haja algum tipo de estipulação, tratava-se de dinheiro de B, que poderia utilizá-lo como quisesse, o que poderia incluir queimá-lo, trocá-lo por bens de consumo ou investi-lo. No entanto, mesmo com uma tal estipulação, A somente retém um interesse de propriedade até que B o utiliza. Isso somente limita como B pode utilizálo em $t_{0}$. Após esse momento, o interesse de propriedade de A sobre esse dinheiro

${ }^{30}$ BLOCK \& BARNETT. Réplica a Davidson sobre a Ética do Descasamento da Maturidade de Empréstimos e o Sistema Bancário de Reservas Fracionárias, p. 421422. 
desaparece, não importa o que aconteça. Como poderia ser diferente? Suponha que você me diga: "Aqui, tome 100 dólares. Agora são seus, porém no prazo de um ano se tornarão meus". O que posso fazer com eles? Nada. Não posso trocá-los, porque sei que voltarão a ser seus novamente. Não posso utilizá-los como dinheiro. Não é como se você estivesse me emprestando um cortador de grama, que posso utilizar sem trocá-lo por alguma outra coisa, e então devolvê-lo após um ano. Em contraste, um "empréstimo" monetário que funcione tal como o empréstimo de um cortador de grama seria inútil ${ }^{31}$. Decerto é permissível que você diga: “aqui estão 100 dólares; quero 110 dólares de volta daqui a um ano, porém você não pode gastar os 100 dólares no cassino, ou emprestá-los a alguém mais por mais do que um ano". Entretanto, depois que eu os trocar, sua reivindicação de propriedade desaparecerá. Eu os terei gastado e o que você disse a respeito do que acontece com eles terá terminado. Sua propriedade dos 110 dólares que eu te devo em um ano não tem nada a ver com o título com respeito aos 100 dólares que você me deu inicialmente.

Conforme Davidson coloca:

O que acontece no final do primeiro ano? Suponha que, em algum momento antes que o empréstimo de A vença, B obtenha 100 dólares de A2 com os quais poderá reembolsar $\mathrm{A}$. A2 transfere estes 100 dólares e seu título para B,

\footnotetext{
${ }^{31}$ Isto nos coloca diante de dois significados distintos para a palavra "empréstimo". Se X empresta seu cortador de grama para seu vizinho Y por 10 dias sem cobrar nada, trata-se de um tipo diferente de contrato do que o que ocorre em um empréstimo monetário. No caso do empréstimo monetário, o tomador do empréstimo deve ter um interesse de propriedade para trocar o dinheiro em questão. Caso não possua esse interesse de propriedade, não poderá trocá-lo e, portanto, não poderá utilizá-lo; o dinheiro lhe será inútil. Entretanto, a utilização do cortador de grama não requer que o "tomador do empréstimo" seja capaz de trocá-lo. Assim, quando X "empresta" o cortador de grama para $\mathrm{Y}$, o que transfere é seu uso, temporariamente, sem transferir seu título. $X$ retém a propriedade total. Com efeito, este exemplo é um contrato de arrendamento com taxa zero por um prazo de 10 dias.
}

sobre os quais A2 obtém [uma nota] contra B. Quando a [nota] original de A vence, torna-se um título - isto é, transforma-se em evidência de uma propriedade - dos 100 dólares [mais juros] que atualmente se encontram em posse de B. Quando a transferência dos 100 dólares é completada, ainda não há duplicação dos títulos de propriedade. A possui os 100 dólares que passaram de $A 2$ para $B$ e de $B$ para A; $B$ ainda possui a [nota] contra $C$, que vence em mais um ano; $C$ possui os 100 dólares originais que passaram de $A$ para $B$ e de $B$ para $C$ há um ano; e A2 possui uma nova [nota] contra $\mathrm{B}$. $\mathrm{O}$ que acontece se $B$ fracassa em assegurar os 100 dólares com os quais reembolsar A antes do final do primeiro ano? É claro que uma de duas alternativas deverá ocorrer: ou B possui outros ativos, equivalentes ao que é devido, situação na qual a [nota] de A se transforma em um título sobre esses ativos, e B deverá entregá-los de imediato. Ou, caso B não possua ativos, a [nota] original de $\mathrm{A}$ permanece e não terá sido cumprida. Neste caso, a [nota] de A não se torna um título imediatamente, dado que $B$ não tem nada, nesse momento, que A possa possuir. B está falido. Neste caso, a [nota] de A somente se torna um título - isto é, se transforma em evidência de propriedade - quando ativos forem produzidos por B.

Acrescento que, no último caso, se $\mathrm{B}$ fracassa em conseguir um empréstimo de A2 e não possui outros ativos, encontrando-se falido, B fica inadimplente e se encontra na mesma situação de qualquer outro devedor falido. Em um mundo libertário, como um empreendedor engajado em BSLL, caso fracasse em antecipar adequadamente o mercado de empréstimos e se torne incapaz de cumprir sua obrigação, poderá ser forçado a trabalhar em uma prisão civil para pagar por sua dívida. Entretanto, em nenhum momento se torna verdadeiro dizer que ocorreu uma duplicação de títulos de propriedade.

Barnett e Block afirmam o seguinte ${ }^{32}$ :

[...] por seu depósito de 100 dólares A recebeu um direito a 100 dólares no futuro, ao término desse ano esse direito venceu e $\mathrm{A}$

${ }^{32}$ BLOCK \& BARNETT. Réplica a Davidson sobre a Ética do Descasamento da Maturidade de Empréstimos e o Sistema Bancário de Reservas Fracionárias, p. 419. 
tem o direito sobre esse objeto, a saber, 100 dólares. Assim, um ano depois da interação comercial inicial, tanto A quanto $C$ têm um direito sobre aquela quantidade de dinheiro presente. A fraude dos contratos incompatíveis ocorreu no início do BSLL e não um ano depois. Ela apenas se revela naquele momento temporal posterior.

No entanto, por que Barnett e Block assumem que a nota em posse de A se torna um título com relação aos 100 dólares originais sendo, portanto, uma duplicação? B apenas concorda em pagar 100 dólares mais juros em $t_{1}$. Por que A deveria se preocupar de onde virá esse dinheiro, dado que seja legitimamente possuído por B nesse momento do tempo e desde que B cumpra com sua obrigação contratual de transferi-lo para A? Se, antes de $t_{1}, B$ tomar um empréstimo de $A 2$, será legitimamente possuído por B, pois A2 terá lhe transferido a propriedade desses 100 dólares. Entretanto, não ocorre conflito no início - em $t_{0}$ - porque A abriu mão da propriedade dos 100 dólares originais e recebeu, em troca, uma nota. Esta nota é evidência de uma obrigação por parte de $\mathrm{B}$ em $\mathrm{t}_{1}$.

Considere o que está envolvido em qualquer empréstimo monetário. Se empresto a um banco 100 dólares por um ano, esta é uma troca voluntária de dois bens presentes que ocorre agora, em $t_{0}$. Não pode ser uma troca entre um bem presente e um bem futuro, porque um bem futuro não pode existir no presente. Mais propriamente, é uma troca entre 100 dólares agora e uma obrigação contratual agora, relativa a dinheiro que será entregue no futuro, porém os 100 dólares e a obrigação são ambos bens presentes (a obrigação assume a forma de uma nota, ou título, ou certificado de depósito, etc.). Por que nos envolvemos nesta troca? Porque, no momento presente, valorizo a satisfação que decorre de ter 100 dólares (mais juros) daqui a um ano mais do que a satisfação derivada dos 100 dólares agora, e o banco estima que os 100 dólares que recebe agora valerão mais do que 100 dólares mais juros daqui a um ano. Esta valoração por parte do banco acontece porque esses 100 dólares serão investidos com alguém mais por dois anos a uma taxa de juros maior. Mantenho qualquer interesse de propriedade sobre os 100 dólares? Não. Troquei-os por uma nota ou certificado de depósito. Meu interesse nesses 100 dólares não é maior do que se os tivesse trocado por um relógio, um telefone ou uma refeição. Eu me importo se o banco utiliza esses 100 dólares para construir parte de uma nova sede ou se os empresta por dois, três ou quatro anos? Não, desde que, quando o empréstimo vencer, o banco conte com dinheiro suficiente, em caixa, para me pagar. Nesse momento, quaisquer 100 dólares mais juros que estiverem em sua posse se tornarão meus e deverão entregá-los. O que acontece se a preferência temporal social tiver aumentado mais do que anteciparam e se tornam incapazes de cumprir com sua obrigação para comigo? Nesse caso, possui qualquer outra coisa que o banco possa ter, cujo valor assim que for liquidado corresponda aos 100 dólares mais juros. Caso não seja capaz de cumprir com isto, incorrerá em um crime.

Como tudo isto difere de um depósito à vista? Se deposito 100 dólares com um banco em uma conta à vista, isso significa que tenho o direito de exigi-los e utilizá-los - isto é, trocá-los com mais alguém - a qualquer momento. Assim, devo continuar a possuílos. Esta é a própria definição de propriedade quando se trata de dinheiro. O dinheiro é singular pois, para utilizá-lo, é necessário ser capaz de trocá-lo e, para trocá-lo, é necessário possuí-lo. Assim, não posso transferir a propriedade desse dinheiro para o banco e tratá-lo como um depósito à vista ao mesmo tempo. Um depósito à vista genuíno em uma sociedade livre não pode ser um empréstimo; é logicamente impossível, uma contradição em termos e equivale a um círculo quadrado. Em uma sociedade livre, pago ao banco uma taxa, em troca da qual o banco se vê obrigado a guardar meu dinheiro em segurança como uma custódia. Caso o banco fracasse nesta obrigação contratual para comigo e trate meu dinheiro como um empréstimo, transferindo 
a propriedade para algum terceiro, terá criado um título de propriedade duplicado. Em uma sociedade livre, este é um ato criminoso, conforme Barnett e Block concordariam.

Entretanto, não há um continuum entre o FRB e o BSLL, como Barnett e Block alegam. Com o depósito à vista, nunca transfiro a propriedade dos 100 dólares. Com o empréstimo a prazo, é o que faço. Uma vez que isto acontece, o banco passa a possuir esses 100 dólares e, assumindo que não há estipulações previamente acordadas, não tenho nada a dizer a respeito do que fará com esse dinheiro. Quando o empréstimo vence, não obtenho de volta um interesse de propriedade nesses 100 dólares, como Barnett e Block parecem imaginar. Como poderia? Não pode existir um contrato de empréstimo onde se acorda que a propriedade total sobre o dinheiro é transferida em $t_{0}$ e a propriedade total sobre o mesmo dinheiro é transferida de volta em $t_{1}$. Isto seria, de fato, uma contradição em termos, pois a propriedade total do dinheiro significa o direito de trocá-lo, ou utilizá-lo de alguma outra forma, sem limites. Ainda assim, é óbvio que precisamente esta limitação seria colocada sobre o dinheiro caso eu me tornasse novamente seu proprietário após $t_{1}$. Se $o$ possui em $t_{1}$, nunca deixei de ter um interesse de propriedade sobre esse dinheiro entre $t_{0} e$ $t_{1}$, pois impedi que o tomador do empréstimo - o banco, neste caso - pudesse utilizá-lo como dinheiro.

Barnette Block gostam de estabelecer uma comparação entre o período que começa após $o$ vencimento do empréstimo inicial em $t_{1}$ sob BSLL e o período que se segue imediatamente ao depósito de dinheiro em uma conta à vista sob o FRB. Sugerem que esses períodos de tempo têm algo em comum em que o credor/ depositante em cada caso possui dinheiro à vista, enquanto ao mesmo tempo o banco terá emprestado este dinheiro para alguém mais. A única diferença, de acordo com Barnett e Block, é que, sob o BSLL, este período de tempo começa mais tarde, enquanto sob o FRB começa imediatamente. Assim, há um continuum. Entretanto, trata-se de uma comparação falsa.
No caso do BSLL, em $t_{1}$ o empréstimo termina. O depositante exige pagamento, mas nem ele, nem o banco fazem qualquer suposição de que o dinheiro devido neste ponto continua a ser um empréstimo. No caso do FRB, o que acontece é precisamente o oposto. Quando o titular da conta deposita seu dinheiro, tanto ele quanto o banco, por um lado, assumem que o dinheiro é à vista e que, portanto, continua a ser possuído pelo depositante, mas, por outro lado, tratam o depósito como o início de um empréstimo para o banco. As duas situações não são comparáveis e não indicam um continuum.

$\mathrm{O}$ que acontece se o vencimento do empréstimo inicial sob BSLL for encolhido para quase zero? Este estado de coisas não se torna o FRB? Não. Suponha que A empresta 100 dólares a B por dez minutos. Pelo menos por esses dez minutos, A não possui esses 100 dólares. Após o término dos dez minutos, exige os 100 dólares mais juros, que $B$ deve pagar. Depois deste momento, nem A, nem B consideram que há qualquer empréstimo efetivamente entre eles. Antes deste momento, A não possui os 100 dólares; B possui. Após este momento, A passa a possuir os 100 dólares mais juros que estão em posse de B, mas não os mesmos 100 dólares que emprestou originalmente. Não é uma questão de duplicação de títulos. Agora, suponha que A deposite 100 dólares com B em uma conta à vista. Suponha que o tempo para retirar os 100 dólares do cofre seja equivalente a dez minutos. Por que isto é eticamente diferente? O fato de ser "à vista" significa que continua a ser possuído por A imediatamente após ter sido depositado. Não obstante possa levar dez minutos para entregar aquilo que está em posse de $B$, ainda será possuído por A. Consequentemente, nem $\mathrm{A}$, nem $\mathrm{B}$ podem tratar legitimamente este dinheiro como um empréstimo em qualquer momento. Caso o façam, como ocorre sob o FRB, necessariamente será possuído ao mesmo tempo por B e por A, dando lugar a um problema de duplicação de títulos. 


\section{VI - ConcLusÃo}

Em sua conclusão, Barnett e Block ${ }^{33}$ levantam a questão dos mercados futuros. Suponha que A concorda em pagar \$X a B daqui a um ano, momento no qual $B$ entregará uma mercadoria $\mathrm{Z}$ para A. Conforme Barnett e Block colocam corretamente, isto cria um contrato com direitos e obrigações, que pode ser vendido. $B$ se encontra contratualmente obrigado a entregar $Z$ no prazo de um ano e A se encontra contratualmente obrigado a entregar $\$$ X nesse mesmo momento. Barnett e Block afirmam que:

Ignorando a margem que cada um deve colocar para assegurar o desempenho, para que ninguém seja prejudicado caso uma das partes se torne inadimplente, não há transferência de dinheiro ou de bens no momento em que o contrato é realizado; em vez disso, cada parte contrai a obrigação de entregar no momento que é especificado para a entrega. Ninguém vendeu nada até que o contrato expire; tudo o que cada um fez foi uma promessa de venda $-Z$ por parte de B e $\$$ X por parte de A. Mas nenhuma parte tem o direito de reivindicar qualquer coisa que seja ( $\mathrm{Z}$ ou $\$ \mathrm{X}$ ) até o momento estabelecido pelo contrato.

Este argumento é falso. Primeiramente, em $\mathrm{t}_{\sigma^{\prime}}$ não é verdadeiro dizer que nenhum bem troca de mãos. Pelo contrário, o acordo cria duas obrigações contratuais distintas, que são bens presentes em si mesmas. Caso não fossem bens, não seriam comprados e vendidos em um mercado secundário, tal como afirmam Barnett e Block. Assim, devem possuir títulos - isto é, podem ser possuídos - mas não são títulos em si mesmos. Não representam a propriedade de outros bens. Mais propriamente: são bens.

Em segundo lugar, quando Barnett e Block dizem que "nenhuma parte tem o

\footnotetext{
${ }^{33}$ BLOCK \& BARNETT. Réplica a Davidson sobre a Ética do Descasamento da Maturidade de Empréstimos e o Sistema Bancário de Reservas Fracionárias, p. 424425.
}

direito de reivindicar qualquer coisa que seja ( $\mathrm{Z}$ ou $\$ \mathrm{X})$ até o momento estabelecido pelo contrato", referem-se a "interesses de propriedade" como na propriedade de Z ou propriedade de $\$ X$. Definindo desta maneira, esta sentença, em particular, é verdadeira: $A$ não possui $Z$ e $B$ não possui 100 dólares até que esses bens sejam trocados em $t_{1}$. Entretanto, não é verdade dizer que $\mathrm{A}$ e $\mathrm{B}$ não possuem títulos até esse momento, caso definamos o título como um compromisso que envolve uma obrigação contratual. Como tais títulos são bens, que podem ser comprados e vendidos, sendo possuídos por $A$ e $B$ desde $t_{0}$ até sua expiração em $t_{1}$, eles têm propriedade. Mas esses títulos não são a mesma coisa que os interesses de propriedade aos quais Barnett e Block fazem referência quando utilizam a palavra "título".

Os contratos futuros envolvem uma troca bidirecional de obrigações em $t_{0^{\prime}}$ que são bens que podem ser comprados e vendidos no mercado. Em um contrato futuro, A valoriza o compromisso que recebe de $B$ mais do que aquele que proporciona a B. B realiza a valoração inversamente. Em $t_{1}$, bens diferentes, a saber, os $\$ \mathrm{X}$ e a mercadoria $\mathrm{Z}$, são trocados.

Este é precisamente o mesmo tipo de compromisso que A recebe de B no contrato de empréstimo monetário, exceto pelo fato de que, com um empréstimo, não se tem uma troca bidirecional de dois contratos; mais propriamente, trata-se de uma reivindicação, na forma de uma nota, que é trocada por dinheiro; por exemplo, 100 dólares. Quando esses dois bens - a nota e os 100 dólares - são transferidos entre as partes em $t_{0^{\prime}}$ essa troca particular é completada. Posteriormente, em $t_{1}$, quando A possui - tem um título sobre - os 100 dólares mais juros que estão em posse de $B$, este é um bem completamente diferente. cos 